Excellence in Performing Arts Research

Volume 4

2017

\title{
Accumulating Capital in Music Education: A Content Analysis of the Music Educators Journal from 2011-2016
}

Rachael Fleischaker

This paper won the Award for Excellence in Graduate Research, 2016-17.

\section{Citation Elements}

Fleischaker, Rachael (2017). Accumulating Capital in Music Education: A Content Analysis of the Music Educators Journal from 2011-2016. Excellence in Performing Arts Research Vol. 4 doi: 10.21038/epar.2017.0401. Retrieved from https://oaks.kent.edu/epar/vol4/iss1/accumulating-capital-music-education-content-analysis-music-educatorsjournal-2011 


\begin{abstract}
This study examined the major topics, focus areas, and targeted age (grade) levels in featured articles appearing in the Music Educators Journal (MEJ) from 2011 to 2016. The MEJ, which every member of the National Association for Music Education receives, is the oldest and most widely distributed music education publication in the United States. Building on Pierre Bourdieu's concepts of cultural capital, this analysis examined featured articles in $M E J$ for implied skills, knowledge, and expertise valuable to its large audience of music educators over the past five years. Results indicate an imbalance in attention given to secondary level performance groups over elementary or tertiary non-performance based classes. Within the performance groups, instrumental received more attention than choral ensembles.
\end{abstract}

\title{
Introduction
}

Music educators have many resources to help them become successful teachers. One of those resources is the $M E J$, a publication that promotes scholarly and practical advice on a variety of issues including teaching philosophies, instructional techniques, and current educational trends (Sage Publishing, 2017b, para. 1). Using this resource could be a way to accumulate the skills and knowledge necessary to advance a musical career. Social theorist, Pierre Bourdieu (1930-2002) termed this cultural capital, which is the idea that there are symbolic elements such as skills, tastes, credentials, and mannerisms, which determine a person's status in certain social orders (Longhofer \& Winchester, 2012). Shared cultural capital creates a sense of group identity. People within the group have varying degrees of status based on the capital that they accumulate. For instance, having a degree from an Ivy League school or having a degree from a community college carries different connotations in different social contexts. Cultural capital can have advantages within a collective group, but it can also hinder an individual's social mobility depending on what social positions that person is trying to obtain.

In Bourdieu's theory, cultural capital manifests in three forms: embodied, objectified and institutionalized (Bourdieu, 1986). Embodied forms of capital refer to traits or characteristics that are noticeable in personal attributes such as grooming, posture, or language patterns. Objectified forms of capital, such as valuable pieces of art, sports cars, or vacation properties, can be converted into economic advantages. Individuals can earn coveted positions of authority or respect by acquiring institutional forms of cultural capital such as degrees or credentials.

The way in which cultural capital is learned or transferred involves habitus. Bourdieu (1990) defined habitus as "acquired, socially constituted dispositions" (p. 13). Individuals learn behaviors, attitudes, or skills through upbringing and through participation in specific social contexts. Thomson (2008) described habitus as the social spaces where cultural capital is learned through interactions, transactions, and events. For instance, understanding that applause between movements of a symphonic work at an orchestra concert is not appropriate, but applauding a soloist during a jazz piece is acceptable behavior.

While habitus is the context for developing cultural capital, doxa refers to the beliefs and values that result from the shared circumstances of a group (Deer, 2008). "Doxa are the silent and unspoken 'rules of the game,' and are maintained by agents within the field" (Dwyer, 2015, p. 95). Doxa can be manifest in individual attitudes, but also in institutionalized practices. When individuals constantly reinforce certain attitudes or beliefs, those traits become accepted and expected. 
Accumulating cultural capital necessitates that a person understands the habitus and the doxa for the desired social position. An example might be the young corporate executive who believes that the only way to a promotion is through extended work hours. If that executive is promoted, then the extra time is deemed worthwhile. The unspoken rules of the game have been reinforced. This type of institutionalized cultural capital transfers to academia as well. Bourdieu (1986) noted that:

Academic qualification, a certificate of cultural competence, confers on its holder a conventional, constant, legally guaranteed value with respect... By conferring institutional recognition on the cultural capital possessed by any given agent, the academic qualification also makes it possible to compare qualification holders and even to exchange them. (p. 248)

If the desired social position is a job in music education, what implicit prior knowledge of educational procedures or musical skill sets are important? Are there hidden rules of the game into which music educators are indoctrinated during their musical training or their work experience? Drawing on the concepts of habitus and doxa, Coulson (2010) explored the idea of cultural capital in music. She used the term musical capital, which she described as:

The interconnected cultural, social, and symbolic assets that musicians acquire and turn to economic advantage in the field of music. These include resources such as musical training and skills, network building, and reputation gained through participation in particular musical events. (p. 257)

Coulson's research suggested that musical capital was accumulated through participation in musical events beginning early in life, access to musical training, supportive environments where musical skills were honed, musical mentors, and entry into musical institutions where licenses to teach music were granted (Coulson, 2010). This investigation explored ways in which musical capital is transmitted or accumulated through a publication that is distributed to every member of a large music education organization.

\section{Purpose}

This study examined the feature articles appearing in the $M E J$ from 2011 to 2016. The $M E J$, which every member of the National Association for Music Education (NAfME) receives, is the oldest and most widely distributed music education publication in the United States (Freer, 2015). The purpose for analyzing this publication was to determine what musical capital is implied through the frequency of article topics, the concentration on focus area (instrumental, choral, general), and the targeted age groups (primary, secondary, or tertiary).

This study was guided by the following questions: 1) What musical capital is implied through the most frequently published topics in the MEJ from 2011 to 2016? 2) What focus areas (i.e. instrumental, choral, and general music) and targeted age groups (i.e. elementary, secondary, tertiary) received the most attention within the articles? 


\section{Procedures}

The $M E J$ has the stated purpose of offering "peer-reviewed scholarly and practical articles on music teaching approaches and philosophies, instructional techniques, current trends and issues in music education in schools and communities" (Sage Publishing, 2017a, para. 1). This analysis focused on MEJ Volume 98, Number 1 (September 2011) through Volume 102, Number 4 (June 2016). This five-year period was selected because it encompassed the most recent completed volumes at the time of the study. Discounting advertisements, each issue was divided between regular departmental columns and feature articles. The departmental columns regularly appearing in these issues included the following:

- President's Message was a column written by the current president of NAfME and appeared in every issue. Presidents Scott Shuler (Volume 98), Nancy Ditmer (Volumes 99-100), and Glenn Nierman (Volumes 101-102) wrote columns addressing various themes or topics which advanced the organization's commitment to support music education.

- From the Academic Editor was written by the editor and highlighted themes or topics for the issue in an attempt to connect them with the NAfME strategic plan or a broader vision of music education. Patrick Freer was the Academic Editor for all five volumes in this analysis. His comments appeared in 19 of the 20 issues. The column for Volume 102, Number 3 was written by guest editor, Michele Kaschub.

- For Your Library appeared in every issue. This column included book reviews by various authors. The publications reviewed in this column pertained to different aspects of music education.

- Take Note appeared in 19 of the 20 issues. It was a dedicated space for announcements from the executive board of NAfME.

- Readers Comments included letters from readers, which were commentary or reactions to previously published material. This feature was included in 18 of the 20 issues.

- NAfME Today was an embedded brochure within the pages of the journal that was featured in 18 of the 20 issues. This brochure stood out visually due to the different color pages and numerous photographs. It focused on news and information from NAfME such as upcoming conferences, newly elected officers, and professional development opportunities.

- Another Perspective was a column added in Volume 98, Number 4. Each of these 17 columns offered editorial comments on current trends and issues in music education or gave a counter perspective to previously printed $M E J$ articles. In its first appearance, an editorial note stated, "the goal of this column is to remind us that great minds sometimes think differently" (Freer, 2012a, p. 30).

- Idea Bank was a column included in 16 of the 20 issues. The purpose of this column was to "present tips from practitioners at all levels" (Sage Publishing, 2017b, para. 2).

- Professional Notes appeared in 13 of the 20 issues. The articles in this column offered a variety of perspectives on current issues, topics, and trends in the music education profession. 
- Collegiate Connections first appeared in Volume 99, Number 1. The column offered any college student or person who prepared college students for music education an opportunity to submit short articles on topics of interest to music educators (Freer, 2012b, p. 35). This column was included in 12 of the following 16 issues.

- Samplings was a column that featured short summaries of various topics that were published in other NAfME publications such as the Journal of Research in Music Education, Update: Applications of Research in Music Education, the Journal of Music Teacher Education, and General Music Today. This column appeared in 11 of the 20 issues.

- Technology for Teaching included product and book reviews focusing on integrating technology into the music classroom. This column was included in six of the 20 issues.

- Measuring Music Teacher Evaluation was a column added in Volume 99, Number 4. The column was described as "an occasional series on assessment and evaluation in music education" (Wilcox, 2013, p. 17). Music educators were encouraged to share stories about what was happening in their school, district, state, or region in response to federal or state teacher evaluation reforms. The column only appeared three more times in the subsequent 12 issues.

- A Century of Evolution only appeared in Volume 100 as it was the centennial year for $M E J$. Each of the four columns included a review of the journal in 25-year increments with a reprint of an article originally published within that 25 -year period.

- Link to Library of Congress was a feature of Volume 102 that highlighted an "on-line resource offering links to over 90,000 digitized items for listening to, playing, and learning about music and its integral role in the telling of American history" (Wintle, 2015 , p. 38). Each of the four columns described a composer or piece of music that could be accessed through this resource.

- Sharing Global Music appeared in only three of the 20 issues. The three columns shared ideas for ways to integrate music from Korea, China, and India into the music classroom.

- Obituary and Memorials, while not a regularly featured column, did appear in Volume 100, Number 3 as a tribute and remembrance of Bennett Reimer for his contributions to music education.

Departmental articles were a mix of scholarly pieces and editorial comments that often complemented the theme for a particular issue or discussed topics that furthered NAfME goals as articulated in the strategic plan. The method for selection or inclusion of these articles was not articulated in the guidelines for submission, and therefore the contents of the departmental articles were not included in the content analysis of this investigation.

The feature articles printed in all $M E J$ publications were required to follow submission guidelines and undergo peer review. The submission guidelines stipulated:

Music Educators Journal (MEJ) is a peer-reviewed journal that encourages music education professionals to submit manuscripts about all phases of music education in schools and communities, practical instructional techniques, teaching philosophy, and current issues in music teaching and learning. The main goal of $M E J$, like that of NAfME, is to advance music education. (Sage Publishing, 2017c, para 1) 
Accumulating musical capital involves an unspoken understanding that various aspects of the music profession should receive more emphasis and that specific skills and knowledge should take prominence over others. Musical capital may be difficult to identify as it can be deeply embedded in the institutional practices and participants' beliefs. Submission guidelines for $M E J$ indicated that all phases of music education were considered as a component to publication. Articles submitted for consideration were refereed by practicing professionals who judged the articles for "importance, originality, timeliness, scope, accuracy, and style" (Sage Publishing, 2017c, para 3). Approximately six articles were selected for publication in each issue (about 24 articles per volume). This study examined the feature articles $(n=142)$ of five volumes of $M E J$ in order to ascertain the forms of musical capital inherent in the publication.

As in similar analyses of music education publications (Killian, 2016; Killian, Liu, \& Reid, 2013; Nichols, 2013; McCarthy, 1999, 2012; Stambaugh \& Dyson, 2016; Yarbrough, 1984, 2002), the content of the feature articles was divided into typographies. After an initial review of the titles, abstracts, and key words in each feature article of all issues, the articles were categorized using existing typologies (Nichols, 2013; Killian, 2016; Stambaugh \& Dyson, 2016), which served as a basis for an additional more in-depth reading of each piece. After reading the content of each article, these broad categories were classified into more specific topics.

For reliability, a second reader was asked to independently place each article into one of the topics or to describe new categorizations as necessary. In the few instances (approximately $3 \%$ of articles) where discrepancies in topics were found, a discussion was held until agreement was reached. There were some articles that could have fit into more than one topic. When that occurred, two criteria were used to make a final determination. The first was in determining the primary intent of the article. The second was a review of the how the title and key words were approached by the author. Each article was only placed in one topic. The 142 feature articles were categorized into 14 topics. These topics included:

- Teaching methods and strategies: any article in which the primary focus was on a particular strategy, method, or technique that could be employed in the music teaching or learning process.

- Curriculum: articles offering specific information on lesson planning, repertoire, materials, or teaching aids.

- Assessment: articles encompassing strategies for measuring or documenting student learning, growth, or musical development.

- Historical: articles whose main emphasis was to offer an historical perspective on any aspect of music teaching or NAfME.

- Social justice: articles with a focus on awareness of inclusion/exclusion of persons or groups involving cultural differences, economic status, social institutions, and similar themes and implications for teaching practices.

- Diversity: articles discussing integration of cross-cultural topics, multiculturalism, and cultural diversity.

- Special learners: articles focusing on strategies, methods, or equipment intended to give students with exceptionalities full and equal access to music education.

- Advocacy: articles grounded in support for or promotion of music education in the schools.

- Cross-discipline: articles integrating music with other aspects of the school curriculum such as literacy, math, science, or other arts. 
- Teacher preparation: articles addressing issues specific to pre-service music educators.

- Technology: articles highlighting technology used in music teaching and learning.

- Recruitment/Retention: articles advising music educators of strategies for recruiting or retaining students in music programs.

- Teacher evaluation: articles focusing on various systems used to assess the effectiveness of music teaching.

- Professional development: articles about engagement in training, education, or advancement of skills and knowledge in music education.

This analysis also looked at the focus areas of each article. The broad categories were instrumental, choral, and general music. These categories were addressed in various combinations throughout the articles. For analysis purposes, focus areas included:

- Instrumental encompassed band, orchestra, or both.

- Choral referred to choir specific articles.

- Ensemble was used when the article was applicable to both instrumental and choral performing groups.

- General music was used if that term appeared in the key words or if the article referred to non-performance based groups or alternative groups (such as guitar bands or recorder choirs) that did not fit into the traditional performance ensemble (band, choir, orchestra) paradigm.

- Broad range denoted articles that could be applied to all focus areas (instrumental, choral, or general music classes).

In addition to the topics and focus areas, articles were also categorized by targeted age group. In many of the articles the targeted age group was listed in the key words. For those that did not list a specific age group in title or key words, the content of the article and context of examples within the article were scrutinized to determine the targeted age category. For the purpose of this investigation, elementary was used to denote students in kindergarten through fifth grade. Middle school was used synonymously with junior high and denoted the age range of fifth grade through eighth grade. High school referred to ninth through twelfth grades. Because some articles referred to combinations of middle school and high school age groupings, this grouping was referred to as secondary. College/university was applied to any tertiary institution. Other was used to denote adults or populations that did not fit into a specific school age grouping. The term all was used when the article was not specific to a particular age group and could be applicable to all age groups.

\section{Findings}

The five volumes under investigation each contained four issues for a total of 20 issues. Total number of articles for the five volumes was $349(N=349)$. As noted, only the feature articles $(n=142)$ were analyzed for frequency of topics, focus areas, and age groups. Frequency counts were computed, but no statistical measures of reliability were used to verify statistical significance. Data was entered in a Microsoft Excel program that was used for coding, sorting, and counting topics, focus areas, and age groupings. 
Three of the issues had a special focus designation. This designation marked a particular theme that was evident in most of the featured articles. The special focus issues included a Centennial Issue (Volume 100, Number 4) marking the $100^{\text {th }}$ year anniversary of the publication, a Military and Music Education Issue (Volume 101, Number 3) which highlighted how music education has been established and practiced in the military, and a Composition Issue (Volume 102, Number 3) advocating ways in which composition can be used in teaching music.

Several other issues had connective themes within the articles, but were not designated as special focus issues. These included themes of spirituality (Volume 98, Number 2), assessment (Volume 98, Number 3), social justice (Volume 98, Number 4), disability and music students (Volume 99, Number 1), rehearsing and practicing (Volume 99, Number 2), composition (Volume 99, Number 3), and standards, evaluation, and assessment (Volume 101, Number 1).

\section{Frequency of Topics}

MEJ published 40 articles that discussed teaching methods and strategies for use in the classroom and during rehearsals (see Table 1). This category represented $28 \%$ of the total feature articles. Articles pertaining to designing, writing, or using curriculum comprised the second highest frequency. Fourteen historical articles made up $10 \%$ of the total number of feature articles. Assessment, social justice, and diversity articles had similar frequency counts of eleven, eleven, and ten respectively which accounted for $8 \%, 8 \%$, and $7 \%$ of the articles. Topics relating to special learners were the focus of eight articles representing $6 \%$ of the featured article topics. Advocacy, cross-discipline, teacher preparation, and technology each had a frequency count of six articles (4\% each of total articles). Recruitment/retention and teacher evaluation were the topic of three articles each for $2 \%$ each of the total. Only one article focused specifically on professional development, which meant that it represented less than $1 \%$ of the total feature articles (see Table 1).

\section{Focus Areas}

Sixty-four of the articles did not specify a focus area. These articles were categorized as broad range, meaning that they could be applicable to all music teaching. Of the 26 articles specific to instrumental performance groups, 18 focused on band, three on orchestra, and five could apply to either band or orchestra. Twenty-two articles concentrated on general music. Twenty articles focused on performance ensembles, but did not specify choral or instrumental. Ten articles were specific to choral groups. Table 2 shows the frequency counts of focus areas within the featured articles.

When analyzing the articles by focus area, three groupings emerged. Performance-based groups encompassed all articles specific to choral, instrumental, or ensemble. General music applied to all articles geared towards classes or groups that were different from the traditional large ensemble such as band or choir. Broad range were articles that applied to both performance-based and general music courses. Figure 1 represents the percentage of articles dedicated to each focus group. 
Table 1. Frequency of Feature Article Topics

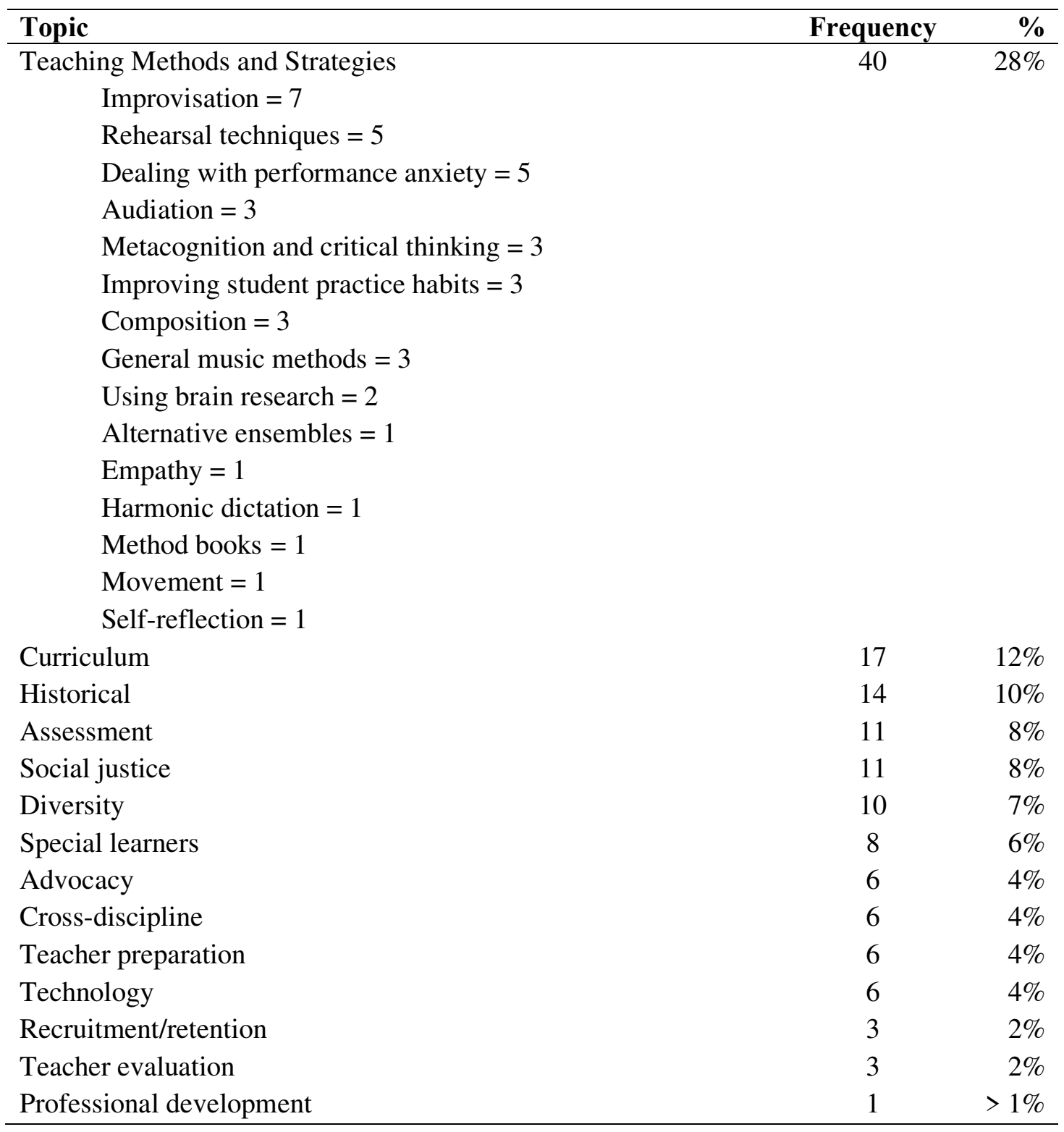

Table 2. Frequency of Focus Area

\begin{tabular}{lcc}
\hline Focus Area & Frequency & Percentage \\
\hline Choral & 10 & $7 \%$ \\
Instrumental & 26 & $18 \%$ \\
$\quad$ Band $=18$ & & \\
$\quad$ Orchestra $=3$ & & \\
$\quad$ Both $=5$ & & \\
Ensemble (Choral and Instrumental) & 20 & $14 \%$ \\
General Music & 22 & $16 \%$ \\
Broad Range & 64 & $45 \%$ \\
\hline
\end{tabular}


Figure 1. Frequency of focus areas by percentage of total articles

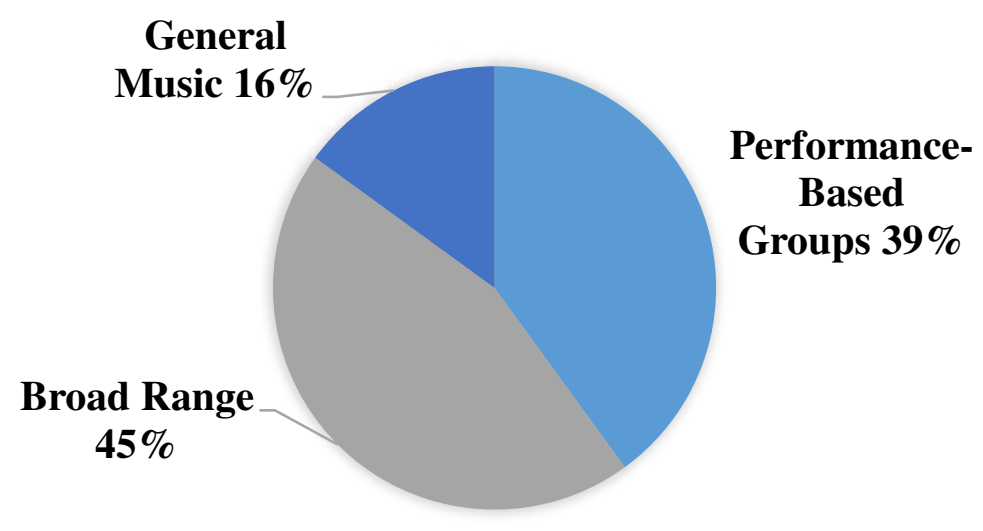

Targeted age groups

Of the 142 feature articles, 63 articles were not targeted to a specific age group. These articles were inclusive of teaching situations for any age or grade. Elementary grades were targeted in 14 of the articles. Middle school only was the demographic for ten articles. Middle school and high school combined were the targeted group in 24 articles. Because the authors of the feature articles often combined middle school and high school ages, secondary was used to include both age groups. Thirteen articles focused on high school. College or university ages (tertiary) were the intended group in 11 articles. Two articles combined high school and college ages. Five articles were specific to adult learners or learners who were outside of the traditional school settings (such a penial institutions). Figure 2 shows consolidated age groupings and their frequency within the featured articles.

Figure 2. Frequency of age groups in featured articles

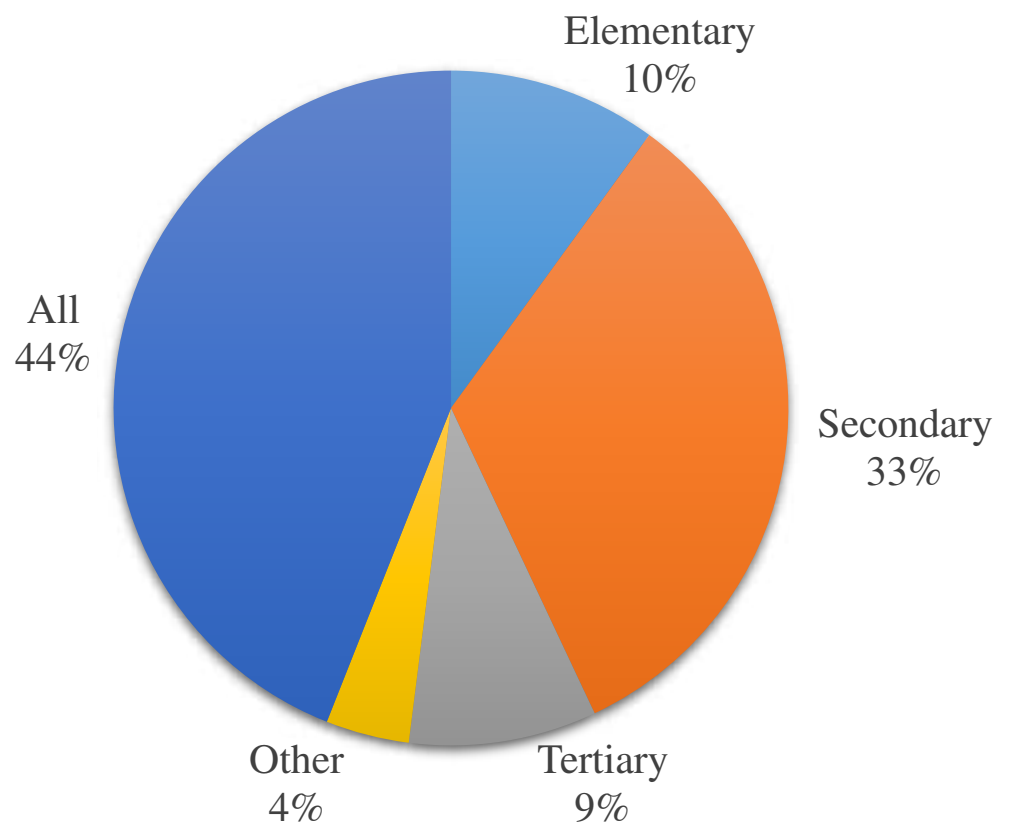




\section{Discussion}

The purpose of this analysis was to determine what topics were most frequently published in the $M E J$ over the past five years and what age groups and focus areas were most frequently noted. As Krippendorff (2013) noted, "the frequency with which a...topic occurs in a stream of messages is taken to indicate the importance of, attention to, or emphasis on that...topic" (p. 62). In terms of musical capital, the importance or amount of attention given to a topic, age group, or focus area implies that individuals with knowledge of those areas have more capital in the profession.

The first research question was concerned with frequency of topics. It was interesting to note that historical topics were the third most frequently published articles. The high number of historical articles could be because the scope of the study included the centennial of the publication. Each issue of Volume 100 celebrated with at least one historically based feature and Volume 100, Number 4 was a special focus issue on $M E J$ 's centennial. In addition to the emphasis on the centennial, Volume 101, Number 3 was a special focus issue devoted to music education and the military, which had many historical articles.

Aside from historical articles, teaching methods and strategies, curriculum, and assessment were the most frequently published topics. These findings suggest that having skills in teaching strategies and knowledge of building curriculum and assessing students are valuable for accumulating musical capital.

The topics of social justice, diversity, and special learners were the next three most frequently published topics. All three topics had comparable frequency counts. Combined, these topics represented $21 \%$ of the featured topics. Looking holistically at the three, the common thread seemed to be a theme of inclusion. Each of the topics advanced a more inclusive approach to music education from three unique perspectives. Social justice topics dealt with inclusion of marginalized populations. Diversity topics sought to include repertoire and teaching styles from a more global perspective. Special learner topics investigated ways to make music class more accessible to all learners. Findings suggested an importance in understanding how to give every learner equity of access to music education.

Musical capital can be expressed by noting what topics are most frequently discussed. The habitus for transmission of musical capital is a metaphorical gateway into the social order. This gateway must have gatekeepers, people who have authority to legitimize beliefs, values, and attitudes. The gatekeepers in this investigation were the peer referees who judged the articles and the academic editor who set the agenda for each issue. The five volumes included in this investigation had the same academic editor who wrote many editorials highlighting the need for music educators to reflect on their teaching not just from a technical standpoint, but from a sociological perspective as well. The specially themed issues that included diversity, social justice issues, and special learners challenged music educators to view music learning as more than the products that are performed on a stage. These issues asked music teachers to reflect on the process of music making through community building. Further research to extend this study, by analyzing another five years of the $M E J$ under a different editor, could potentially explore the influence of editorial leadership in the publication.

Teacher evaluation, recruitment/retention, and professional development were the least frequently published topics. In terms of musical capital, it would seem that these topics were not as important as teaching methods and strategies. However, since the conditions that affect each of these topics vary from state to state and school to school, perhaps their absence is due to a lack 
of universal characteristics between various teaching contexts. $M E J$ is a national publication. Articles that were specific to a state or region may not have been selected for publication because they were more appropriate for state music association publications. Professional development was addressed in the journal, but mainly in the departmental column NAfME Today, which advertised for professional development opportunities provided by the organization.

The most revealing results were found while attempting to answer the second research question of what focus areas and age groups are given the most attention in $M E J$ articles. In terms of focus area, nearly half of the featured articles (45\%) encompassed a broad range of music teachers. Many articles discussing teaching methods, history, advocacy, assessment, curriculum, social justice, and special learners were applicable to all areas of music teaching. However, of the remaining articles, a large amount (39\%) were focused on performance-based ensembles indicating that teachers of traditional ensembles have more musical capital or status in the profession. Only $16 \%$ of the total articles were specific to general music, giving those teachers less capital in terms of attention in a major publication.

The targeted age groups again showed that nearly half of the featured articles (44\%) were inclusive of a broad range of students. One limitation of the study worth noting is that most authors did not give exact age ranges, so the lines between elementary/middle school and middle school/high school were not sharply drawn. For instance, fifth grade may have been included in articles about elementary general music practices or could have been applied to beginning band in middle school settings. However, secondary age groups clearly received more attention with $33 \%$ of the articles. Elementary age groups were targeted in only $10 \%$ of the articles with tertiary groups at $8 \%$. This seems to indicate that teaching at the secondary level would accumulate the most musical capital.

The intent of this investigation was to determine what forms of musical capital are implied in $M E J$ articles to better understand possible biases inherent in the music education field. Understanding that musical capital, like cultural capital, is often embedded in the institution and rarely questioned by the participants, an examination of documents produced by an institution may indicate what is deemed important or necessary for success. In terms of age group and focus area, findings suggested an imbalance in attention given to secondary level performance-based classes over elementary or tertiary groups. Instrumental ensembles received more attention than choral ensembles.

The knowledge and skills necessary for acquiring the requisite amount of musical capital to be successful in teaching music deserves attention individually and collectively as the music education profession continues into its next 100 years of music teaching. Further research could broaden the scope of the study by adding five-year increments of content, which would provide a means for comparing trends in topics, focus areas, and age groups. As Killian (2016) so aptly stated, "we should continue on the path we have begun: encouraging open, frequent, and rigorous examination of what we do as music teacher(s)" (p. 12). This would include examining what constitutes musical capital in publications, such as $M E J$, that are distributed to music educators. 


\section{References}

Bourdieu, P. (1986). The forms of capital. In J.G. Richardson (Ed.), Handbook of theory and research for the sociology of education (pp. 241-260). New York, NY: Greenwood Press.

Bourdieu, P. (1990). In other words: Essays towards a reflexive sociology. Stanford, CA: Stanford University Press.

Coulson, S. (2010). Getting 'capital' in the music world: Musician's learning experiences and working lives. British Journal of Music Education, 27(3), 255-270.

Deer, C. (2008). Doxa. In M. Grenfell (Ed.), Pierre Bourdieu: Key Concepts (pp. 113-130). Durham, UK: Ashgate.

Dwyer, R. (2015). Unpacking the habitus: Exploring a music teacher's values, beliefs and practices. Research Studies in Music Education, 37(1), 93-106.

Freer, P. (2012a). Editorial note. Music Educators Journal 98(4), 30. doi:10.1177/0027432115599531

Freer, P. (2012b). Editorial note. Music Educators Journal 99(1), 35. doi:10.1177/0027432112454837

Freer, P. (2015). "Let us give the light to them": Bookending the first century of Music Educators Journal. Journal of Historical Research in Music Education 36(2), 111-128.

Killian, J.N. (2016). Looking back: Topics published in JMTE 2010-2016. Journal of Music Teacher Education, 26(1), 7-12.

Killian, J.N., Liu, J., \& Reid, J.F. (2013). The Journal of Music Teacher Education: A content analysis of articles 1991-2011. Journal of Music Teacher Education, 22(2), 85-99.

Krippendorff, K. (2013). Content analysis: An introduction to its methodology ( $3^{\text {rd }} \mathrm{ed}$.). Thousand Oaks, CA: Sage Publications, Inc.

Longhofer, W., \& Winchester, D. (Eds.). (2012). Social theory rewired (2 ${ }^{\text {nd }}$ ed.). Retrieved from http://routledgesoc.com

McCarthy, M. (1999). A content analysis of articles in the first twenty volumes. The Bulletin of Historical Research in Music Education, 20(3), 181-202.

McCarthy, M. (2012). Developments and trends in historical research as reflected in the Journal of Historical Research in Music Education. Journal of Historical Research in Music Education, 33(2), 152-171.

Nichols, B.E. (2013). The first 20 years: A content analysis of the Journal of Music Teacher Education, 1991-2011. Journal of Music Teacher Education, 22(2), 73-84.

Sage Publishing. (2017a). Music Educators Journal: Aims and scope. Retrieved from https://us.sagepub.com/en-us/nam/music-educators-journal/journal201900\#aims-andscope

Sage Publishing. (2017b). Music Educators Journal: Description. Retrieved from https://us.sagepub.com/en-us/nam/music-educators-journal/journal201900\#description

Sage Publishing. (2017c). Music Educators Journal: Submission guidelines. Retrieved from https://us.sagepub.com/en-us/nam/music-educators-journal/journal201900\#submissionguidelines

Stambaugh, L.A., \& Dyson, B.E. (2016). A comparative content analysis of Music Educators Journal and Philosophy of Music Education Review (1993-2012). Journal of Research in Music Education, 64(2), 238-254.

Thomson, P. (2008). Field. In M. Grenfell (Ed.), Pierre Bourdieu: Key Concepts (pp. 67-81). Durham, UK: Ashgate. 
Wilcox, E. (2013). Editorial note. Music Educators Journal 99(3), 17. doi:10.1177/0027432112470071

Wintle, J. (2015). Stars, stripes, and Sousa: Songs of America. Music Educators Journal, 102(1), p. 38.

Yarbrough, C. (1984). A content analysis of the Journal of Research in Music Education, 19531983. Journal of Research in Music Education, 32(4), 213-222.

Yarbrough, C. (2002). The first 50 years of the Journal of Research in Music Education: A content analysis. Journal of Research in Music Education, 50(4), 276-279. 